\title{
DE STEEKPROEF IN DE ACCOUNTANTSCONTROLE III
}

\author{
door P. C. Louwers
}

\section{BEPALING VAN EEN PRINCIPIEEL STANDPUNT}

\section{Inleiding}

De in het hierna volgende neergelegde gedachten zijn ontstaan in nauwe samenwerking met Prof. A. Goudeket; zij zijn het resultaat van een ernstige poging tot onderzoek van de betekenis die nieuwere inzichten zouden kunnen hebben voor de verdere beroepsontwikkeling zonder dat de grondslagen waarop het beroep in Nederland berust daarmee worden aangetast.

\section{Wat is een steekproef?}

De steekproef werd in het voorgaande gedefinieerd als de partiële waarneming van een te onderzoeken massa met het doel de typische eigenschappen van de gehele massa te leren kennen zonder alle eenheden waaruit die massa bestaat te onderzoeken. De steekproef is dus een statistische methode waarmede op grond van de waarneming en analyse van een deel der te onderzoeken gegevens conclusies kunnen worden getrokken ten aanzien van het geheel.

Men pleegt de steekproeven als volgt te onderscheiden:

1) de gewone of eenvoudige steekproef, waarbij men ten aanzien van aard en aantal van de gekozen eenheden geheel willekeurig te werk gaat;

2) de kritische steekproef, waarbij men zich ten aanzien van aard en aantal van de gekozen eenheden richt op kritische, dat wil zeggen op voor het beoogde doel kenmerkende punten. Daarbij kan onderscheid worden gemaakt tussen de volgende gevallen:

a) alle in een bepaald tijdvak uitgevoerde boekingen worden gecontroleerd:

b) de boekingen betrekking hebbend op bepaalde transacties worden van het begin tot het einde gecontroleerd;

c) alle boekingen boven een bepaald bedrag worden onderzocht;

d) alle boekingen met een ongewoon karakter worden geverifieerd;

3) de "wiskundige" steekproef, waarbij zowel de aard en de omvang van de waarnemingen als de analyse van de betekenis van de met de steekproef verkregen resultaten worden gebaseerd op de waarschijnlijkheidsrekening.

\section{Betekenis van de eenvoudige en van de kritische steekproef}

Zoals gezegd, wordt de eenvoudige of - minder vriendelijk - primitieve steekproef gekenmerkt door het feit dat men zich zowel voor wat betreft de keuze van aard en omvang als voor wat de interpretatie van het resultaat betreft, laat leiden door ,,intuïtief aanvoelen", een weinig objectief uitgangspunt dus.

Hoewel ook bij de kritische steekproef dit ,,intuïtief aanvoelen" een zekere rol speelt, komen daarbij toch meer doelbewuste overwegingen naar voren. Dergelijke steekproeven zijn immers ,"kritisch" in die zin dat zij in het bijzonder zijn gericht op die boekingen, waarin men op grond van zijn kennis omtrent de cijferreeks verwacht dat het te onderzoeken verschijnsel zich zou kunnen voordoen, of op die onderdelen van een te onderzoeken reeks, die in het bijzonder het eindresultaat kunnen beïnvloeden.

Bij het gesprek over de betekenis van de kritische steekproef voor de 
accountant speelt vaak een terminologische verwarring een rol. In de leer van de organisatie wordt namelijk ook als kritische steekproef aangeduid de $100 \%$-waarneming die op een zogenaamd kritisch moment plaats vindt. Een bekend voorbeeld daarvan is de controle van het produktie-proces, waarbij men veelal aan het einde van een produktie-gang ineens alle daarvó̀r liggende handelingen controleert. Een ander voorbeeld is de inventarisatie van bulkgoederen op het moment dat deze in een minimum-positie verkeren. Het zal duidelijk zijn dat deze kritische "steekproef" betrekking heeft op een geheel ander probleem dan het steekproevenvraagstuk, waarmee dit artikel zich bezig houdt. In feite gaat het hier om een $100 \%$-waarneming en niet om het verkrijgen van een oordeel omtrent het geheel uit de kennis van een deel.

$\mathrm{Bij}$ de kritische steekproef ontstaat het gevaar van een cirkelredenering: het onderzoek van de kritische gevallen moet uitsluitsel geven over de structuur van de totaliteit, maar de keuze van de kritische gevallen is slechts mogelijk wanneer men het algemene beeld van de massa al kent. Zodra de accountant zich dus in zijn voorstelling van de kritische gevallen vergist komt hij tot onjuiste conclusies.

Zowel Kleerekoper als Carman hebben daarom geconcludeerd dat noch de eenvoudige noch de kritische steekproef geschikt zijn voor het verkrijgen van een representatief beeld van de massa. (Vance en Neter komen voor bepaalde omstandigheden tot een hiervan afwijkende conclusie.)

\section{Waaruit bestaat de conventionele steekproef?}

Welke plaats neemt de conventionele steekproef in het hierboven aangegeven schema in?

In de praktijk ruimt de accountant in zijn controleprogramma een plaats in voor de zogenaamde "steekproefsgewijze beoordeling", waaronder dan wordt verstaan het "doorlopen" van documenten of onderdelen van de administratie ("to scrutinize/scan the documents and accounts") en het nader onderzoeken van hetgeen bij deze waarneming om de een of andere reden opvalt. Theoretisch is het mogelijk dat bij dat „doorlopen" en ,steekproefsgewijze beoordelen" geen aanleiding wordt gevonden ook maar één post nader te onderzoeken. Ook zonder wiskundige bewijsvoering weet de accountant dat hij op grond van een dergelijke waarneming natuurlijk geen oordeel kan uitspreken en hij zal daarom in zijn controleprogramma opnemen dat ook wanneer hem geen bijzondere posten opvallen - toch altijd een bepaald deel, bijvoorbeeld $\mathrm{x} \%$ van het aantal posten of in een ander geval y boekingsdagen per maand, bij wijze van steekproef moeten worden gecontroleerd. Daarbij zal hij er dan meestal voor zorgen dat in ieder geval de grote posten in zijn waarneming worden betrokken.

Hoewel de „wiskundige" steekproef reeds vele jaren een bekend hoofdstuk uit de theorie van de accountanscontrole vormt, kan worden gesteld dat deze voor de beroepsuitoefening in Nederland tot nu toe weinig praktische betekenis heeft. Wanneer de accountant dus spreekt over steekproeven $z a l$ hij in het algemeen een combinatie van de eenvoudige en de kritische steekproef op het oog hebben.

\section{Betekenis van de ,wiskundige" steekproef}

Met onmiskenbare kracht van argumenten hebben de statistici gesteld dat de conventionele steekproeven-techniek van de accountant hoewel natuurlijk niet waardeloos toch wel uitermate dubieus is en dat het hoog tijd wordt dat de accountant zijn onwetenschappelijke werkwijze gaat vervangen 
door een meer verantwoorde steekproevenmethode. Zo er in de accountantscontrole plaats is voor de steekproef, aldus de statistici, dan zijn daarbij zuiver statistische problemen aan de orde en statistische problemen moeten met statistisch verantwoorde middelen worden opgelost. De statisticus Arkin merkt schamper op dat de accountants weliswaar plegen te fulmineren tegen alle onvoldoende gefundeerde handelingen in de door hen gecontroleerde bedrijven, maar dat het accountantsberoep zelf zowel de keuze van de steekproevenmethode als de bepaling van de omvang van de steekproef heeft overgelaten aan de grillen van de individuele accountant, aan op onnaspeurbare wijze ontstane tradities bij de specifieke controle-objecten en aan een bijgelovig vertrouwen in bepaalde percentages die voldoende zekerheid zouden geven. Arkin zegt dat de accountants een onbegrijpelijk vertrouwen blijken te hebben in het percentage 10 en toont dan aan dat dit percentage in het ene geval belangrijk te hoog en in het andere belangrijk te laag is.

De accountant daartegenover is van oordeel dat de statisticus niet het belang begrijpt of erkent van het terecht van vitale betekenis geachte persoonlijke element in de beroepsuitoefening. Ondanks de meest overtuigende wiskundige bewijzen is bij de accountant - ook in Amerika - altijd het gevoel blijven bestaan dat de "koude mathematische steekproeventechniek" hem op de een of andere manier toch niet de nodige zekerheid kan verschaffen en dat de conventionele steekproeventechniek hem meer kans geeft zijn persoonlijke inzicht en ervaring de rol te laten spelen, die voor zijn gevoel bij het gebruik van de "wiskundige" steekproef verloren dreigt te gaan. De ervaren accountant wijst dan vaak op het feit dat hij erin slaagt met een soort zesde zintuig juist de foutieve posten uit een te controleren reeks "te pikken".

Enerzijds is de accountant er dus niet in geslaagd tegenover de koele bewijzen van de statisticus andere dan gevoelsargumenten naar voren te brengen, anderzijds is het de statisticus niet gelukt de plaats van het persoonlijke oordeel van de accountant in het kader van de ,wiskundige" steekproef op voor de accountant aanvaardbare wijze te markeren.

\section{De verhouding statistiek-controleleer}

Het gebruik van statistische hulpmiddelen, waaronder dat van de ",wiskundige" steekproef, bij de accountantscontrole heeft geen enkele principiële invloed op de controletechniek als zodanig. Statistische methoden kunnen voor de accountant alleen hulpmiddelen zijn voor de oplossing van zijn steekproef-problemen, dat wil zeggen voor het bepalen van de rationele omvang van zijn waarnemingen in het geval hij bepaalde toleranties in zijn oordeel omtrent de kwaliteiten van de te controleren massa kan aanvaarden, maar zij kunnen nooit een oplossing brengen voor problemen, die in wezen de controletechniek betreffen.

Het potentiële voordeel van de ,wiskundige" steekproef is enkel dat men kwantitatief kan aangeven welk risico men loopt dat het met de steekproef waargenomen deel geen representatief beeld biedt van de gehele massa. De vraag of deze kennis van enige praktische betekenis is, is een puur controletechnisch vraagstuk, omdat de aard van elke controlemaatregel moet worden afgewogen tegen de functie, welke die controlemaatregel heeft in het kader van het totale beeld van de te controleren massa.

Een voorbeeld moge dit demonstreren.

Neem aan dat in een bepaald geval voor de saldo-bevestiging van debiteuren gebruik wordt gemaakt van de zogenaamde negatieve methode en dat 
de saldo-bevestigingen slechts in steekproeven aan de debiteuren worden verzonden. Wanneer men nu aan de hand van de ontvangen antwoorden op grond van statistische methoden zou willen vaststellen hoeveel verschillen door de debiteuren zouden zijn gesignaleerd indien dergelijke saldobevestigingen aan alle debiteuren zouden zijn verzonden, dan moet men $z$ ich eerst een oordeel vormen over de doelmatigheid van deze controletechniek als zodanig. Daarover kan de waarschijnlijkheidsrekening geen enkele opheldering geven. Indien bijvoorbeeld zou moeten worden aangenomen dat de gemiddelde debiteur niet reageert, ook niet wanneer het saldo onjuist is, dan is elke statistische bewerking van de binnengekomen antwoorden zonder de geringste betekenis.

Niet de statisticus dus, maar uitsluitend de accountant kan de vraag beantwoorden of een bepaalde steekproef al of niet effectief is, met andere woorden: alleen de accountant kan aangeven of deze controletechniek in dit specifieke geval tot het gewenste oordeel kan leiden. Wanneer de accountant daarbij gebruik wil maken van de "wiskundige" steekproef is hij gedwongen kwantitatieve normen vast te stellen, die een weerspiegeling moeten zijn van het oordeel dat hij met de betrokken controlehandeling wil verkrijgen. Men mag daarbij uiteraard niet iedere afzonderlijke controlehandeling op zichzelf beschouwen, maar men moet alle controlehandelingen in hun onderling verband zien; men moet exact vaststellen wat een fout is, welke betekenis een fout heeft en wanneer een reeks cijfers als goed en wanneer zij als onaanvaardbaar moet worden gekwalificeerd; men moet nauwkeurig weten welk risico men wil lopen dat het in steekproeven gecontroleerde deel geen representatief beeld geeft van de gehele massa. Al deze vragen zullen slechts kunnen worden beantwoord, indien de accountant exact kan aangeven welke zelfstandige, aanvullende, afrondende of aansluitende betekenis deze specifieke controlehandeling in het gehele complex van controlehandelingen inneemt.

Wanneer die vragen zijn beantwoord, is de vaststelling van het voor die controle geschikte steekproevenschema een relatief eenvoudige, technische aangelegenheid geworden.

\section{De steekproef en de volkomen controle}

Het aloude probleem bij het gesprek over de mogelijke betekenis van de steekproef in het kader van een volkomen controle is dat van de zogenaamde homogeniteit van de door de accountant te onderzoeken cijfers (de constantheid dus van de algemene voorwaarden voor het optreden van het waar te nemen verschijnsel).

Wat toch is het geval? De accountantscontrole houdt zich bezig met het onderzoek van cijfers, die de kwantitatieve voorstelling zijn van bedrijfshandelingen; bedrijfshandelingen nu zijn gebeurtenissen die door de wil en het inzicht van mensen worden bepaald. Steeds weer wordt betoogd dat deze omstandigheid een zodanige invloed op de waarschijnlijkheid van de gelijkvormigheid van de afzonderlijke, gelijksoortige bedrijfshandelingen heeft dat de statistische eis van homogeniteit van de massa in het kader van de accountantscontrole nooit zal kunnen worden vervuld.

Wanneer men de verschillende groepen van cijfers waarmee de accountant wordt geconfronteerd zonder meer als de statistische massa kwalificeert, is dit ongetwijfeld volkomen juist, maar wanneer men zich realiseert dat een volkomen controle alleen beoogt het onderzoeken van die gegevens, welke voor het met die controle beoogde doel van betekenis zijn, dan is het probleem op die wijze onjuist gesteld. 
In het kader van een volkomen controle heeft de accountant de taak enerzijds vast te stellen dat zich geen afwijkingen hebben voorgedaan van zo danige omvang dat zij het te onderzoeken beeld van de cijfers wezenlijk zouden hebben beïnvloed (zekerheidsoordeel) en anderzijds zich de stellige overtuiging te verwerven dat het systeem en de werking van de interne controle gedurende de te onderzoeken periode zodanig zijn geweest dat ook afwijkingen die voor het met de controle beoogde doel niet van wezenlijke betekenis zijn, zouden zijn gesignaleerd (waarschijnlijkheidsoordeel).

Voortbouwend op een door Limperg in het kader van diens leer der organisatie met betrekking tot de controlemiddelen van de dirigerende leiding gemaakte indeling zou de gerichtheid van de accountantsarbeid die nodig is voor de vervulling van een specifieke functie tegen de achtergrond van het organische verband tussen alle controlehandelingen als volgt kunnen worden onderscheiden:

a) de stelselmatige keuze van de relatief belangrijke momenten;

b) de kritische keuze van de symptomatische momenten;

c) het onderzoek van het overblijvende.

In het raam van een volkomen controle immers:

- moet de accountant van de te onderzoeken cijfermassa een zodanig deel op een zodanige wijze zelfstandig waarnemen als nodig is om de mate van zekerheid te verkrijgen die vereist is gezien de betekenis welke die cijfers hebben in het kader van de doelstelling van het onderzoek (stelselmatige keuze van de relatief belangrijke momenten);

- moet de accountant steunend op zijn vakbekwaamheid en ervaring, zijn algemene kennis van het te controleren bedrijf en zijn specifieke kennis van de te onderzoeken cijfermassa vaststellen welke cijfers of cijfergroepen van die massa hij als onwaarschijnlijk, zwak, merkwaardig, gevaarlijk, enzovoort beschouwt en dus diepgaand moet onderzoeken (kritische keuze van de symptomatische momenten):

- moet de accountant het overblijvende zodanig onderzoeken als nodig is om de stellige overtuiging te verwerven dat de interne controle in de te onderzoeken periode dusdanig is geweest, dat de juistheid van de niet specifiek onderzochte posten waarschijnlijk is.

Als iedere schematisering dreigt ook deze indeling teveel te schabloniseren. Met name is het niet zo dat de beide eerste bewerkingen geen betekenis zouden hebben voor het verkrijgen van een oordeel omtrent de interne controle of dat het oordeel omtrent de als derde genoemde groep van cijfers geen invloed zou kunnen hebben op het oordeel omtrent de beide eerstgenoemde groepen.

In het voorgaande is nog niet aan de orde geweest het onderscheid in de zin zoals dat bij de huidige algemene beroepsopvattingen gebruikelijk is, namelijk dat de steekproef alleen gerechtvaardigd zou zijn indien de uitkomst van die steekproef geen essentiële betekenis heeft voor het zekerheidsoordeel, met andere woorden dat de steekproef alleen voor toepassing in aanmerking komt voor het onderzoek van gegevens ten aanzien waarvan met een waarschijnlijkheidsoordeel kan worden volstaan.

Het hierboven besprokene met betrekking tot de steekproef als zodanig, de verhouding statistiek - controleleer en de verhouding steekproef - volkomen controle heeft de basis gelegd om op dit centrale vraagstuk nader in te gaan. De conclusie moge vooropstaan: bij de plaatsbepaling van de steekproef als hulpmiddel bij de accountantscontrole bestaat aan dat onderscheid mijns inziens geen behoefte.

m a b blz. 276 
Bezien we daartoe eerst het begrip ,,zekerheidsoordeel". Dit begrip heeft slechts een betrekkelijke betekenis. Het gaat daarbij immers alleen om die zekerheid, welke ten aanzien van de betrokken groep van cijfers is vereist in het kader van de plaats welke die cijfers hebben in de doelstelling van het onderzoek. Het gaat dus noch om de juistheid van de individuele gegevens waaruit die groep cijfers bestaat noch om de absolute juistheid van het beeld dat die cijfers bieden. Dit betekent dat de accountant dus ook en aanzien van de zekerheid omtrent een groot aantal gegevens, die tenslotte alle een bepaalde invloed hebben op het uiteindelijke beeld, zekere toleranties kan aanvaarden, hetgeen ook ten behoeve van het zekerheidsoordeel onder bepaalde, geanalyseerde omstandighdeen de weg opent voor statistische controle-methoden, waaronder steekproeven. Alleen in het geïsoleerde geval dat iedere individuele boeking van betekenis kan zijn voor het eindoordeel dat men met het onderzoek wil bereiken zal een boekingsgewijze waarneming altijd onontkoombaar blijven.

Het is in dit verband interessant vast te stellen dat "homogeniteit" niet een begrip met een vaste inhoud blijk te zijn. Dit begrip zal immers ten aanzien van dezelfde gegevens een andere inhoud kunnen hebben naar gelang het doel dat met de controle wordt beoogd. Zo zal de inhoud een andere zijn wanneer de controle uitsluitend is gericht op het certificaat bij de jaarrekening dan wanneer zij is gericht op een onderzoek in het kader van de adviserende functie. Binnen het raam van eenzelfde doelstelling zal de inhoud van dat begrip ruimer worden naarmate de onderneming groter wordt omdat enerzijds de invloed van de individuele post op het beeld van de totaliteit steeds naar een ander niveau verschuift en anderzijds de betekenis van de organisatie (interne controle) voor de accountant groter wordt. Het blijkt derhalve dat bij het onderzoek van de vraag of een bepaalde massa homogeen van samenstelling kan worden geacht zowel met principiële als met proportionele aspecten rekening moet worden gehouden.

Opgemerkt wordt nog dat door het treffen van bepaalde administratieftechnische maatregelen de homogeniteit van het te onderzoeken materiaal doelbewust kan worden bevorderd.

Zowel op controle-theoretische als op statistische gronden blijkt tenslotte dat de steekproef alleen in aanmerking komt indien het gaat om de waarneming van massale gegevens. Controle-theoretisch omdat bij een gering aantal samenstellende gegevens elk individueel gegeven een essentiële invloed heeft op de totaliteit, statistisch omdat de vereiste omvang van de steekproef bij een te kleine massa de omvang van de massa zal benaderen.

Het voorgaande leidt tot de overtuiging dat het onjuist is te stellen dat de steekproef niet zou passen voor die onderdelen van het onderzoek die in het kader van een volkomen controle tot een zekerheidsoordeel moeten leiden. Het onderzoek naar de betekenis van de steekproef voor de accountant is of dient te zijn een onderzoek naar de organische plaats die de steekproef kan innemen in het geheel van controlemiddelen waaruit een volkomen controle bestaat.

\section{„Wiskundige" steekproef versus volledige waarneming}

Is het inderdaad waar dat een volledige waarneming een absolute en in ieder geval een grotere zekerheid biedt dan de steekproef? Op het eerste gezicht lijkt dit een overbodige vraag maar bij nadere bestudering blijken zich aspecten voor te doen die een verder onderzoek rechtvaardigen. Het is 
immers slechts theoretisch waar dat een volledige waarneming tot ontdekking van alle fouten zal leiden. Door allerlei oorzaken, waarvan die van de verminderende concentratie wel de belangrijkste is, zullen ook bij de volledige waarneming fouten aan de aandacht ontsnappen. Het staat bepaald niet vast dat de zeer intensieve controle waartoe het in steekproeven waarnemen van een relatief gering aantal gevallen als onderdeel van een organische controle aanleiding geeft, niet een beter inzicht in de betrouwbaarheid van de te onderzoeken cijfers zal kunnen verschaffen dan een zeer extensieve controle die als gevolg van het volume slechts weinig diepgang kan hebben en bovendien als gevolg van onvermijdelijke monotonie van het werk tot een verslapping van de aandacht, anders gezegd tot ,controle-blindheid", aanleiding geeft. Vance merkt terecht op dat de ontdekking van bijvoorbeeld een fraude meer afhankelijk is van de waakzaamheid waarmee de waargenomen documenten en boekingen worden onderzocht dan van de vraag of men alle documenten en boekingen heeft gezien. Afgezien van het bekende verschijnsel dat het ,,met verstand waarnemen" van reeds in tegraal door lagere assistenten geverifieerde massale cijferreeksen vaak tot verrassende resultaten leidt, behoeft men slechts weinig ervaring te hebben met het opstellen van een programma voor het uitvoeren van een ,wiskundige" steekproef om tot de conclusie te komen dat de voorbereiding van een dergelijke steekproef een verdieping in alle aspecten van de totale massa en de wijze waarop het totale cijferbeeld tot stand kwam (de organisatie) noodzakelijk maakt die bij de volledige waarneming structureel niet aan de orde komt. De invloed op de controle die uitgaat van het opbouwen van verantwoorde steekproevenschema's is dan ook vergelijkbaar met de invloed die op de kwaliteit van de organisatie uitgaat van bijvoorbeeld de analytische werkzaamheden voorafgaande aan het opstellen van een budget en het voor bereidend onderzoek bij het mechaniseren van de administratie.

Het vraagstuk ,steekproeven of volledige waarneming" biedt echter nog een ander uiterst belangrijk gezichtspunt.

In het kader van de gebruikelijke werkverdeling binnen het accountantskantoor kan in het algemeen worden gesteld dat de volledige waarneming van massale cijferreeksen plaats vindt door de lagere categorieën van assistenten.

$\mathrm{Nu}$ doet $z$ ich in de praktijk een merkwaardig verschil voor tussen de toepassing van de conventionele en die van de ,,wiskundige" steekproef. Zodra immers de waarneming niet meer volledig is maar in het controleprogramma wordt vermeld dat een steekproef moet worden uitgevoerd, zullen die werkzaamheden door een hogere categorie van assistenten worden verricht dan wanneer diezelfde werkzaamheden een volledige waarneming zouden betreffen. Dit is een gevolg van het feit dat de conventionele steekproef grotendeels een kritische steekproef is, waarbij de feitelijke waarneming samenvalt met de slechts op grond van vaktechnisch inzicht te beantwoorden vraag ,.wat moet ik waarnemen?" $B_{i j}$ de ,,wiskundige" steekproef daarentegen wordt die vraag in alle details vooraf door de leider van de controle beantwoord en dat antwoord vindt zijn neerslag in het programma voor de assistent.

Het is een grote attractie van de ,wiskundige" steekproef dat een veel sterker accent komt te liggen bij de leiding van de controle (op het niveau van de accountant), waardoor enerzijds de betrouwbaarheid van de waarneming van de massale cijferreeksen belangrijk minder afhankelijk wordt van de voortdurende waakzaamheid van juist de lagere categorieën van

m a b blz. 278 
assistenten en anderzijds ook de aard en omvang van de steekproef die door de hogere assistenten moet worden uitgevoerd op grond van een vakbekwame analyse in het controle-programma moet worden vastgelegd. De planning van de aan elk controle-onderdeel te besteden tijd kan daardoor bovendien op exactere overwegingen berusten en er ontstaat een reëlere basis voor de instructie en de supervisie van de assistenten door de verantwoorde lijke accountant.

Het is een open vraag of de kwalitatieve verbetering van de controle, die van het gebruik van de "wiskundige" steekproef het gevolg kan zijn, niet ruimschoots opweegt tegen de grotere zekerheid die men bij volledige waarneming op grond van de gedachte ,meer werk - dus meer zekerheid" meent te verkrijgen. Het antwoord op deze vraag kan slechts worden gegeven door herhaalde schaduwbewerking met steekproeven van controles die conventioneel door integrale waarneming plaats vinden.

Het vraagstuk van de steekproef ten opzichte van de volledige waarneming heeft uiteraard ook een kostenaspect. Wanneer een gegeven doel met een partiële waarneming kan worden bereikt, betekent die partiële waarneming - in vergelijking met een volledig onderzoek - uiteraard een werkbesparing en zal zij dus de economisch-rationele werkwijze zijn. Uit het voorgaande moge echter gebleken zijn dat het uitvoeren van een .,wiskundige" steekproef niet alleen betekent dat minder posten worden onderzocht, maar ook dat „,meer werk aan minder posten" moet worden besteed. Zelfs indien men zou aannemen dat bij de steekproef ten aanzien van de individuele post hetzelfde onderzoek zou plaats vinden als bij de volledige waarneming zullen de kosten per waargenomen eenheid van de steekproef in het algemeen hoger liggen dan voor de integrale waarneming, omdat bij de steekproef niet „,voor de voet” kan worden waargenomen, maar iedere eenheid overeenkomstig het steekproef-plan moet worden opgezocht. Ten opzichte van de totaliteit ontstaat echter een kostenvoordeel, zonder dat van een kwaliteitsvermindering sprake behoeft te zijn.

Het is in dit verband interessant waar te nemen dat men in Amerika op grond van uitgebreide onderzoekingen in bepaalde gevallen heeft geconcludeerd dat de interne controle van inkoopfacturen en van verkoopfacturen, de waardering van goederenvoorraden (bedrijfseconomisch en fiscaal), de verloning, het manen van debiteuren en dergelijke bij een steekproefsgewijze behandeling belangrijk goedkoper worden terwijl toch voldoende betrouwbare resultaten worden verkregen. Zelfs wordt vermeld dat bijvoorbeeld luchtvaartmaatschappijen zijn overeengekomen de berekening van het elk hunner voor hun transporten toekomende niet meer op grond van een integrale maar op grond van een met steekproeven uitgevoerde calculatie te doen plaats vinden. De deelnemers aan een van die overeenkomsten vermelden dat zij op die manier gezamenlijk jaarlijks een bedrag van $f 2$ miljoen administratiekosten besparen. Dit heeft zelfs aanleiding gegeven tot het ontstaan van het nieuwe begrip ,inductief administreren".

Indien ondernemingen derhalve reeds zover gaan dat zij in bepaalde gevallen de steekproef voldoende betrouwbaar achten om ter bereiking van het kostenvoordeel hun financiële verhouding tot derden op grond van steekproefresultaten te regelen, bestaat er alleszins aanleiding tot nadere bezinning op de vraag welke plaats aan de steekproef moet worden toegekend in de accountantscontrole, die zich immers binnenkort zelfs zal moeten bezighouden met cijfers die op grond van dergelijke steekproeven zijn tot stand gekomen. 


\section{.Wiskundige" steekproef versus conventionele steekproef.}

Duidelijk moge uit het voorgaande zijn gebleken, dat het principiële voordeel van de "wiskundige" steekproef gelegen is in de objectieve kennis van de mate van waarschijnlijkheid dat het in steekproeven onderzochte deel een representatief beeld van de totaliteit biedt.

Gewezen werd ook zowel op de verdieping van de controle als op het $z$ waardere accent op de leiding van de controle waartoe het opstellen van verantwoorde steekproeven-schema's aanleiding kan geven omdat de „wiskundige" steekproef door zijn aard dwingt tot een voorafgaande gedetailleerde analyse van hetgeen men in steekproeven wil waarnemen.

In de praktijk zal een gevonden fout bij de "wiskundige" steekproef ook een objectievere betekenis krijgen dan bij de conventionele steekproef. $\mathrm{Bij}$ laatstgenoemde moet immers bij elke fout een subjectieve interpretatie plaats vinden van de betekenis van die fout voor het totaal. Automatisch komt men er dan toe die fout als iets op zichzelf staands te beschouwen (,,laat maar lopen") en dus onvoldoende relatie te leggen met het beeld van de totaliteit. Bij de ",wiskundige" steekproef heeft geen enkele fout een zelfstandige betekenis.

Wat het aantal steekproeven betreft menen Amerikaanse onderzoekers te mogen concluderen dat de accountants in het ene geval belangrijk meer en in het andere belangrijk minder steekproeven uitvoeren dan in feite nodig zou $z$ ijn om de zekerheid te verkrijgen die zij zeggen in het kader van hun controle nodig te hebben. Gemiddeld, zo menen zij, zal echter een geringer aantal „wiskundige" steekproeven nodig zijn.

De verdere ontwikkeling van de beroepsopvattingen met betrekking tot de plaats van de "wiskundige" steekproef zal kunnen leiden tot een grotere uniformiteit in de beroepsuitoefening en daardoor wellicht ook tot algemeen aanvaarde, meer exacte gedachten ten aanzien van de grenzen van de verantwoordelijkheid van de accountant.

Een recente publikatie van het American Institute of C.P.A. (a case study on the extent of audit samples) waarin duidelijk tot uitdrukking komt het afwijkende inzicht van enige vooraanstaande Amerikaanse accountants ten aanzien van hetgeen in een bepaalde casus-positie nu precies zou moeten worden gedaan, bevat te dien aanzien bepaald leerzame gegevens.

\section{Conclusies}

1) Wanneer een gegeven doel met een partiële waarneming kan worden bereikt, betekent die partiële waarneming - in vergelijking met een volledig onderzoek - uiteraard een werkbesparing en zal zij dus de economisch-rationele werkwijze zijn. Dergelijke gedachten gaven destijds Belle aanleiding onderscheid te maken tussen ethische en economische groeperingen onder de accountants, maar Belle ging daarbij niet uit van de overweging dat de accountant ten behoeve van het maatschappelijk verkeer een zelfstandig oordeel moet verkrijgen en dus in van geval tot geval te bepalen omvang zelfstandige waarnemingen moet verrichten, maar van de gedachte dat accountantsarbeid louter duplicering van reeds verrichte (interne) controle-arbeid is. Het voorgaande moge hebben aangetoond dat Kleerekoper c.s. met recht tegen deze steekproeven ten strijde trokken.

Het is in dit verband redelijk de beoordeling van de artikelenreeks van

$\mathrm{m}$ a b blz. 280 
Kleerekoper te plaatsen tegen de achtergrond van de tijd waarin zij werd geschreven. Niet alleen blijkt bij nauwkeurige bestudering daarvan dat Kleerekoper de steekproef niet absoluut verwerpt, maar ook dat werd uitgegaan van geheel andere verhoudingen dan die waarmee het beroep thans wordt geconfronteerd.

Er heeft een ontwikkeling plaats gehad in de inzichten ten aanzien van de verantwoordelijkheid van de accountant, de kwantitatieve verhoudingen zoals die zich thans in vele bedrijven voordoen waren toen in Nederland onbekend, de interne organisatie van de ondernemingen heeft een enorme ontwikkeling ondergaan en tenslotte zijn noch de techniek van de accountantscontrole noch die van de steekproef stil blijven staan.

2) De huidige beroepsinzichten erkennen dat de steekproef ten aanzien van de gegevens waarvoor met een waarschijnlijkheidsoordeel kan worden volstaan een verantwoorde plaats kan innemen in een volkomen controle. Aangezien de steekproef in de praktijk in Nederland in feite gemeengoed is, zou de Nederlandse accountant dit uitgangspunt ook niet in volle waarachtigheid kunnen verwerpen. De wijze waarop de steekproef wordt gehanteerd is echter te opportunistisch en daardoor onvoldoende gefundeerd.

3) Alleen bij de ,wiskundige" steekproef verkrijgt men een objectief inzicht in de mate van waarschijnlijkheid dat het beeld van de totaliteit gelijk zal zijn aan het beeld dat men zich daarvan op grond van de steekproef vormt. Men mag daarbij de steekproef niet als een op zichzelf staand controlemiddel beschouwen, maar moet rekening houden met de organische verbondenheid van alle middelen.

De hantering van de "wiskundige" steekproef kan daarenboven een zodanige invloed op de kwaliteit van de controle hebben dat de vraag rijst of deze steekproef onder bepaalde omstandigheden ook in vergelijking met de volledige waarneming niet tot een grotere in plaats van tot geringere zekerheid zal leiden (betere voorbereiding van de controle, voorkoming van controle-blindheid, verdieping in de wijze waarop het cijferbeeld tot stand kwam, sterker accent op de leiding van de controle).

4) Exactheid is slechts een betrekkelijk begrip en exactheid heeft slechts een betrekkelijke waarde. De accountant moet er bij voortduring voor waken dat hij niet streeft naar exactheid om der wille van de exactheid. $\mathrm{H}_{\mathrm{ij}}$ dient zorgvuldig te overwegen welke graad van nauwkeurigheid in elk gegeven geval werkelijk is vereist; hij moet voorkomen dat hij een in wezen zuiver cijfermatige exactheid nastreeft, die noch controletechnisch vereist noch economisch zinvol is.

Dit betekent dat de accountant ook voor het onderzoek van gegevens ten aanzien waarvan hij een zekerheidsoordeel moet verkrijgen gebruik zal kunnen maken van de steekproef. De accountant behoeft immers noch ten aanzien van de individuele gegevens noch ten aanzien van de verschillende groepen van cijfers een grotere zekerheid te verkrijgen dan nodig is gezien de plaats welke die cijfers in het kader van het doel van het onderzoek innemen. Slechts wanneer elk individueel gegeven als zodanig een wezenlijke invloed op het beeld van de te onderzoeken totaliteit heeft, zal een volledige waarneming altijd onontkoombaar blijven. 
Het voorgaande mag niet worden opgevat als zou worden gepropageerd dat onder alle omstandigheden zonder meer gebruik zou kunnen worden gemaakt van steekproeven, maar wel dat de steekproef onder daarvoor geschikte omstandigheden en in organische verbondenheid met alle andere controlemiddelen een plaats kan innemen in een volkomen controle.

\section{Besluit}

De steekproefproblemen waarmee de accountant wordt geconfronteerd zijn ook naar het oordeel van vooraanstaande statistici (o.a. Prof. Arkin, hoogleraar statistiek en statistisch adviseur van Price, Waterhouse $\mathcal{E}$ Co.) van dien aard dat zij een nieuwe en specifieke benadering noodzakelijk maken. Grondige gecombineerde research van accountants en statistici is het aangewezen middel tot verdieping van het inzicht; de bereidheid van de individuele accountants om door experimenten in de praktijk daartoe bij te dragen en hun ervaringen openbaar te maken is daarvoor een vereiste.

Voor wat betreft de werkzaamheden gericht op het verkrijgen van een waarschijnlijkheidsoordeel is het mogelijk en naar ons oordeel vereist de weinig gefundeerde conventionele steekproef op korte termijn door een meer verantwoord steekproevensysteem te vervangen, enerzijds omdat met de "wiskundige" steekproef objectief inzicht in de vereiste omvang van de steekproef en de resultaten van de waarneming wordt verkregen, anderzijds omdat zowel de voorbereiding als de uitvoering van de "wiskundige" steekproef zodanige eisen stellen dat een meer betrouwbare conclusie het gevolg zal zijn. Ook voor wat de op het zekerheidsoordeel gerichte arbeid betreft hebben wij op grond van de uiteengezette overwegingen de overtuiging dat de ,wiskundige" steekproef in principe een plaats kan krijgen en zelfs dat de controle met behulp daarvan tot "grotere zekerheid" zal kunnen leiden.

Het spreekt vanzelf dat te dien aanzien pas een algemene beroepsopvatting zal kunnen ontstaan, nadat de resultaten van enige jaren veelzijdig experimenteren zullen hebben bevestigd dat de "wiskundige" steekproef op de in dit opstel uitgewerkte wijze integrale aanwending bij de accountantsarbeid kan vinden.

Een resumé in het Frans en Engels van de 3 bijdragen van de heer P. C. Louwers over .,De steekproef in de accountantscontrole" zal worden geplaatst in het juli-nummer. 